\title{
Analysis of stock market based on cellular automata
}

\author{
Fucun LIU ${ }^{1, a}$, Zhiyong CAI ${ }^{2, b}$ \\ ${ }^{1}$ School of Computers, Guangdong University of Technology Guangzhou, Guangdong, 510006, \\ China \\ ${ }^{2}$ School of Computers, Guangdong University of Technology Guangzhou, Guangdong, 510006, \\ China \\ aliufch@gdut.edu.cn, bjams.and1@qq.com
}

Keywords: Cellular Automata , Risk Hobby , Stock Market Volatility , Long-term investments .

\begin{abstract}
In this paper, a new cellular-automata-based stock market model is constructed. Differing from the previous models, this model takes amount of investors' capital, the important factor, as a normally distributed random variable, into account. By combining with the characteristics of the current stock market and classifying the market investors, a random process to divide risk preferences is introduced, and two corresponding trading strategies are presented to more effectively simulate the real stock market. Through simulation study, it is deduced that the excessive speculation of investors is the critical factor of sharp fluctuations in the stock market, which is not conducive to the return of the fair value of the stock. At the same time, the average yields of the two investor types are compared, and it is concluded that there is no long-term investment value in current China's stock market and appropriate short-term investment can improve the return on investment.
\end{abstract}

\section{Introduction}

The stock market is a typical complex adaptive system, the evolution of the stock market price by more than one individual uncertainty and macro and micro factors involved in the decision. So far, financial theorists still lack a recognized securities pricing models [1].

In recent years, many Chinese and foreign scholars have conducted in-depth stock market research, and since 2000, Chinese scholars Ying Shangjun [2,3,4] established the first cellular automaton model of single stocks, verify the existence of the stock market price volatility and aggregate yields peak fat-tail phenomenon. Later, there have been scholars have established different models, Gao Jianxi [5] has established a psychological investor and stock trading volume cellular automaton model, studies have shown that: the lack of communication with others under investor information, the stock market activity will reduce.

\section{Model}

Cellular automata model [6] have cellular space, cellular state, neighbors in the form and evolution of the rules and other factors.

(1) Cellular (equity investors) are divided into two types: Based on the fundamentals of trading stock investors, the paper referred to as long-term investments (also called value investors), the other is a short-term investors (also known as Investment person)..

(2) Cellular space is a two-dimensional grid. For simplicity, this space might be setto simulate the space of a single stock.

(3) Neighbors form usually have the following form Neighbor: This model uses extended form Moore neighbor type, that is, each investor is surrounded by 24 neighbors.

(4) Cellular state space Assume cellular state variables to their trading volume, trading volume is positive, negative, and zero, respectively investors to buy, sell and hold transactions. 
(5) The rules of evolution: the current state of unit cells affected by two factors, the investment behavior of neighbors and their own first factor.

Most of the time a neighbor on the behavior of a certain probability affect the current cellular; secondly, the investor's own investment preferences, such as whether self-confidence as well as their degree of risk-loving, with a certain probability affect the trading behavior of investors.

\section{The average system trading strategy}

Most investors believe that technical trend, once formed, will continue, unless the technology trends go bad, so the model technical investors use the average system as the trading strategy,setting trading rules as follows:

(1) When the stock price along the day (and generally 5,10,20) averages upward, investors may next decision is to buy stocks.

(2) When the stock price fell below the average effective support along the average down, the decision-making behavior of investors is likely to sell the stock.

(3) When the stock price above the moving average and the moving average angle (we called from the penetration rate) greater than $45^{\circ}$, the decision-making behavior of investors is to sell the stock .

(4) when the stock price below average and the average angle of less than $-45^{\circ}$, the decision-making behavior of investors may be buying stocks .

Let $\theta$ from penetration rate function:

$$
\theta=\frac{p^{t}-\bar{p}}{\bar{p}}, \bar{p}=\frac{1}{n} \sum_{t-n}^{t-1} p^{i}
$$

$$
O_{i, t}^{\sigma}=\left\{\begin{array}{c}
\text { We can get the volume formula: } \\
K_{m e}\left(\frac{1}{n} \sum_{i=1}^{n} Q_{i, t}\right) \frac{k_{s}}{\theta} \frac{M_{i t}}{\mu}, 0<\theta<\frac{\pi}{4} \text { 或 }-\frac{\pi}{4}<\theta<0 \\
K_{m e}\left(-\frac{1}{n} \sum_{i=1}^{n} Q_{i, t}\right) \frac{k_{s}}{\theta} \frac{M_{i, t}}{\mu}, \theta<-\frac{\pi}{4} \text { 或 } \theta>\frac{\pi}{4}
\end{array}\right.
$$

Based maker pricing mechanism to determine the price, are:

$$
P^{t+1}=\left(1+\gamma \psi_{c}^{t}\right) P^{t}+\frac{C_{p} Q^{t}}{N}
$$

(3)Combined with the market maker system, provided the investor market fundamentals and technicals investors proportion of people were $n_{j z}$ and $n_{j s}$,let $m=n_{j z}-n_{j s}$,

Then $n_{j z}=\frac{1+m}{2}, n_{j s}=\frac{1-m}{2}$. Combining Equation (9) can be obtained price update rule formula:

$$
P^{t+1}=\left(1+\beta \psi_{c}^{t}\right) P^{t}+\frac{C_{p}}{2 N}\left[(1+m) Q_{j z}^{t}+(1-m) Q_{j s}^{t}\right]
$$

\section{Simulation study}

\subsection{Value set}

Unless otherwise specified, the parameter values according to Table 1. 
Tab.1 Setting of several main parameters

\begin{tabular}{c|c|c|c|c|c|c|c|c}
\hline$k_{\text {me }}$ & $P^{0}$ & $\alpha$ & $\beta$ & $\mu$ & $C_{p}$ & $N$ & $\gamma$ & $k_{s}$ \\
\hline 0.008 & 100 & 120 & 0.01 & $5^{\star} 10$ & 1.05 & $10^{3}$ & 0.01 & 0.01 \\
\hline
\end{tabular}

\section{2 stock price}

In a real financial market, there is a very famous 28 principles of law, so we were taken $m=-0.6, \quad m=0, m=0.6$ the three scenarios.

Tab.2 Price volatility under different evolutionary mechanisms(100 independent experiments)

\begin{tabular}{c|c|c|c|c}
\hline Evolutionary mechanisms & minimum price & maximum price & average price & Mean square deviation \\
\hline$m=-0.6$ & 75.63 & 147.34 & 108.56 & 35.78 \\
\hline$m=0$ & 87.55 & 133.74 & 112.48 & 26.65 \\
\hline$m=0.6$ & 96.28 & 132.59 & 116.38 & 15.33 \\
\hline
\end{tabular}

Observation of Table 2, we can conclude that: (1) price volatility: $m=-0.6>m=0>$ $m=0.6$,When technical investors accounted for the majority of the stock price is highly unstable and prone to acute up plunge, shares a serious deviation from its fundamental value, when the majority of investors in the market fundamentals, stock prices stabilized, gradually return to the basic values; (2) because the model is based on imitation mechanism, so when the market investment when departing from the general who carried out the fundamentals of the stock fundamentals investor strategy, imitate each other will not lead to abnormal price fluctuations, which the literature [4] obtained herd behavior in the market led investors to imitate each other and thus make the stock price volatility abnormal different conclusions. Investors in what investment strategy is an important factor leading to fluctuations in the market .

\subsection{Yield Simulation}

The average rate of return investors fundamentals:

$$
\lambda_{j z}^{t}=\frac{\sum_{i=1}^{t}\left(p^{i}-p^{i-1}\right) Q_{j z}^{i}}{\mu N n_{j z}}
$$

The average rate of return investors technical:

$$
\lambda_{j s}^{t}=\frac{\sum_{i=1}^{t}\left(p^{i}-p^{i-1}\right) Q_{j s}^{i}}{\mu N n_{j s}}
$$

Using Computer software to simulate the average yield obtained two types of investors as follows:

Tab.3 Different average yield under evolutionary mechanisms (100 independent experiments)

\begin{tabular}{c|c|c|c}
\hline $\begin{array}{c}\text { Evolutionary } \\
\text { mechanisms }\end{array}$ & $\begin{array}{r}\text { Minimum of } \\
\lambda_{t}^{s}-\lambda_{t}^{f}\end{array}$ & $\begin{array}{r}\text { Maximum of } \\
\lambda_{t}^{s}-\lambda_{t}^{f}\end{array}$ & Average of $\lambda_{t}^{s}-\lambda_{t}^{f}$ \\
\hline$m=-0.6$ & -0.064 & 0.328 & 0.328 \\
\hline$m=0$ & -0.051 & 0.263 & 0.157 \\
\hline$m=0.6$ & -0.035 & 0.115 & 0.052 \\
\hline
\end{tabular}


Observe in table 3 can be found in three technical investors yields overall to be higher than the technical investors, namely technical investors easily in the market obtain excess profits.Analysis is not difficult to get out of the technical side of investors in the transaction to follow the principle of selling stocks below the average,therefore, when the market appears to be more volatile time to avoid risks, reduce losses, and the fundamentals of investors in the market when the risk of a larger fluctuations may appear passive.But the fundamentals of investors in a more stable operation of the market has a certain advantage, do not need frequent operations, so how to make the two trading strategies better combination is worth thinking about a direction.

According to table 3 we found that with the increase of the fundamental investors, technical investors to obtain excess profit decreases gradually, it is not difficult to draw the advantages of greater market volatility technical investors will become increasingly obvious, easy access to more excess profits. So we can technically investors dominated the market will bring more excess profits for the technical investors, but also bring abnormal stock price fluctuations, is not conducive to the stability of the market.

\section{Conclusion}

This paper constructs a new cellular automata model of stock price behavior made intuitive description. Obtained by the conclusions are as follows:(1) Technical investors excessive speculation is likely to cause greater volatility in the market, the share price rises and falls, seriously out of the fair value of the stock, which is not conducive to market stability and the true value of the stock return. Regulators need to strengthen supervision, so that more long-term investment value of listed companies, which is conducive to long-term development of the capital market;(2) The average yield of the stock market investors than fundamentals of technical investors, This reference value for investors investment, China's stock market has just started soon, the average rate of return investors in the stock market is higher than the technical fundamentals of investors, There are many immature place, may not have good long-term investment value, the appropriate short-term investments is an effective way to increase revenue.

\section{References:}

[1] SUN Youfa, ZHANG Chengke, GAO Jiangguang, el al. Study of modern security pricing model[J]. Systems Engineering Theory \& PracTice,2007,27(5):11.(in Chinese)

[2] YING Shangjun, WEI Yiming, FAN Ying, et al. Study on Complexity in stock market based cellular automata[J]. Systems engi neering- Theory \& Practice,2003,23(12):18-24.(in Chinese)

[3] YING Shangjun, FAN Ying, WEI Yiming, et al.An investment-analysis-based cellular automata model for evolving simulation in stock market[J]. Management Review, 2004,16(11):4-9.(in Chinese)

[4] YING Shangjun, FAN Ying, WEI Yiming. A CA model for single stock market and its dynamical analysis[J]. Systems Engneeing,2006, 24(7):31-36.(in Chinese)

[5] GAO Jianxi, DONG Hongguang, LIU Yuanyuan, et al. Analysis and simulation of stock market based on cellular automata investors' choice psychology and stock' trading amount[J].Mathematics in Practice and Theory,2009(2):6-12.(in Chinese)

[6] TAO Shuang. Application of cellular automata in the financial field[J].Times Finance,2014,(7):68 -69.(in Chinese) 